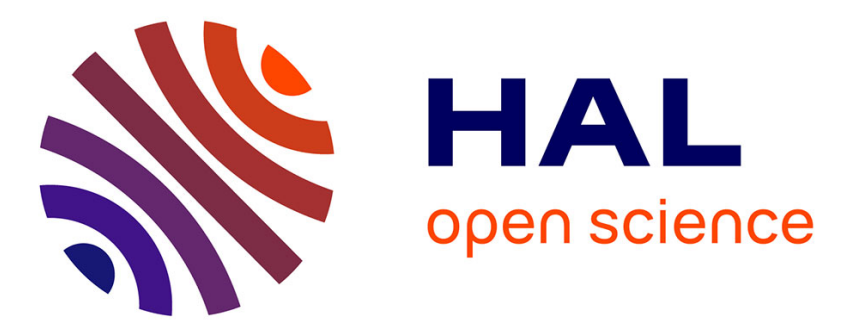

\title{
Molecular analysis of parasitoid linkages (MAPL): gut contents of adult parasitoid wasps reveal larval host
}

- Rougerie, R., - Smith, A., - Fernandez-Triana, J., Carlos Lopez-Vaamonde, Ratnasingham, S., - Hebert, P.D.N.

\section{- To cite this version:}

- Rougerie, R., - Smith, A., - Fernandez-Triana, J., Carlos Lopez-Vaamonde, - Ratnasingham, S., et al.. Molecular analysis of parasitoid linkages (MAPL): gut contents of adult parasitoid wasps reveal larval host. Molecular Ecology, 2010, 20 (1), pp.179-186. 10.1111/j.1365-294X.2010.04918.x . hal-02655938

\section{HAL Id: hal-02655938 \\ https://hal.inrae.fr/hal-02655938}

Submitted on 29 May 2020

HAL is a multi-disciplinary open access archive for the deposit and dissemination of scientific research documents, whether they are published or not. The documents may come from teaching and research institutions in France or abroad, or from public or private research centers.
L'archive ouverte pluridisciplinaire HAL, est destinée au dépôt et à la diffusion de documents scientifiques de niveau recherche, publiés ou non, émanant des établissements d'enseignement et de recherche français ou étrangers, des laboratoires publics ou privés. 


\title{
Molecular analysis of parasitoid linkages (MAPL): gut contents of adult parasitoid wasps reveal larval host
}

\author{
RODOLPHE ROUGERIE, ${ }^{*}$ M. ALEX SMITH,${ }^{*}$ JOSE FERNANDEZ-TRIANA, ${ }^{*}$ CARLOS LOPEZ- \\ VAAMONDE, + SUJEEVAN RATNASINGHAM* and PAUL D.N. HEBERT* \\ *Biodiversity Institute of Ontario, University of Guelph, 50 Stone Road East, Ontario, Canada N1G 2W1, +Institut National de \\ la Recherche Agronomique, UR0633 Zoologie Forestière, F-45075 Orléans, France
}

\begin{abstract}
Metamorphosing insects often have complex and poorly known life histories. In particular, what they feed on during their larval stages remains unknown for the vast majority of species, and its documentation only results from difficult and time-intensive field observations, rearing or dissections. Through the application of a DNA analysis of gut contents in adult parasitoid wasps, we were able to selectively sequence a diagnostic DNA marker that permitted the identification of the host used by these wasps during their larval stages. By reproducing these results in species with different life histories, we excluded other potential sources of host DNA, confirming that after ingestion by the parasitoid larva the host DNA can persist through metamorphosis in the abdominal contents of the adult wasp. Our discovery considerably extends the applicability of molecular analysis of gut contents by enabling the documentation of food used by insects during their larval stages and thus increasing the accuracy and precision of food web studies. The $24 \%$ success rate of our approach is surprisingly high considering the challenging context for host DNA preservation, and we discuss the factors possibly affecting this rate. We propose molecular analysis of parasitoid linkages (MAPL) as a new method to document host-parasitoid associations at a faster pace and with unrivalled precision. Because of the key regulatory role of parasitoid wasps in ecosystems, which makes them the most commonly used biological control agents, MAPL will have immediate applications in both basic and applied biological sciences.
\end{abstract}

Keywords: biological control, food web, host-parasitoid associations, Hymenoptera, Lepidoptera

Received 8 July 2010; revision received 17 September 2010, 1 October 2010; accepted 6 October 2010

\section{Introduction}

The predator-prey relationships of insects are among the most poorly documented links of terrestrial food webs. In any given terrestrial environment, their alpha diversity is often several orders of magnitude higher than any other group of animals. Our understanding of the variety of services they provide and of the complexity of their interrelationships is at best rudimentary. Among insects, the parasitoid wasps are involved in

Correspondence: Rodolphe Rougerie, Fax: 1519824 5703;

E-mail: rrougeri@uoguelph.ca highly complex, yet poorly understood, networks of relationships with their host species (Godfray 1994). We regularly seek to exploit these relationships and regulate the populations of herbivorous insects (Eveleigh et al. 2007), through the biological control of pest or invasive species using monophagous parasitoid species. However, our understanding of host-parasitoid relationships is generally poor, and this impediment is accentuated by a considerable deficit in the necessary taxonomic knowledge. As a typical example, in a recent tropical survey of parasitoid wasps, Smith et al. (2008) showed that $95 \%$ of the species are likely to be undescribed and that most of them are highly host specific, a 
result contrasting with previous assumptions of fewer species with generalist feeding behaviour (polyphagous). This scenario of currently unappreciated diversity is not restricted to the tropics (Smith et al. 2009), and a new paradigm is emerging regarding the prevalence of specialist vs. generalist parasitoid wasp species-the latter is not as common as is frequently thought. It appears that the molecular characterization of evolutionary units and ultimately DNA-assisted taxonomy represent the most appropriate way to reliably assess species richness in these megadiverse groups. In this context, we investigated how molecular analysis of gut contents, a powerful emergent technique to unravel food webs (Sheppard \& Harwood 2005; King et al. 2008; Dunshea 2009), could offer an alternative solution to the time-consuming rearing experiments or repeated field observations traditionally required to document host-parasitoid relationships. Rearing experiments usually require decades of effort to deliver detailed insights at a local scale (Eveleigh et al. 2007; Smith et al. 2008; Janzen et al. 2009), and this ultimately impedes the ecological feedback into large-scale biodiversity surveys (Smith et al. 2009). Thus far, the use of molecular methods to link parasitoid wasps and their hosts has been primarily limited to detection purposes, that is targeting parasitoid DNA within the host through the use of specific primers (Weathersbee et al. 2004; Gariepy et al. 2007, 2008; Traugott \& Symondson 2008). Such an approach generally requires a priori knowledge of the identities of both the parasitoid and its host, a situation largely inapplicable in the field. Here, we propose to use the DNA extract derived from the abdomen of the adult wasp to identify both the wasp and the host it used to complete its larval development. If successful, when collecting an adult parasitoid wasp whose host is completely unknown, this approach would permit host identification simply by analysing the wasp's guts, assuming that host DNA does persist through metamorphosis in its abdominal contents. Adult parasitoid wasps are generally nectar feeders (Jervis et al. 1992, 1993), a biological trait that fortuitously precludes "contamination" of gut contents by secondary predation, although feeding on nonhost prey by females of synovigenic species is known and could possibly impede the use of our approach in some cases.

We focused our work in identifying a primer set likely to amplify degraded, semi-digested DNA (Greenstone et al. 2007) targeting a short DNA fragment that would show near-universal binding in the main groups of hosts (Lepidoptera and Diptera), while being near-universally exclusive for parasitoid wasps. Because this DNA fragment must be species diagnostic, we selected a short fragment in the COI mitochondrial gene region used as a standard "DNA barcode" for species-level identification in animals (Hebert et al. 2003b). Additionally, the ongoing development of large reference libraries of DNA barcodes for both parasitoids and their hosts (Smith et al. 2008, 2009; Hebert et al. 2010) makes our approach immediately applicable. In this work, we used three species of wasps with distinct life histories to establish whether host DNA persisted through metamorphosis or whether host tissues ingested during or after the emergence of the adult wasp are a required source of host DNA for our approach to be successful. All three species were reared or collected from previously identified hosts, so that the results of the gut content analysis can be controlled and confirmed unambiguously.

\section{Materials and methods}

\section{Primer selection}

DNA barcoding campaigns, focusing on a standard DNA fragment for species identification across a broad range of taxa, require the development of near-universal primers (Hajibabaei et al. 2005). The tens of thousands of specimens processed at the Canadian Centre for DNA Barcoding (CCDB) for ongoing large-scale campaigns targeting parasitoid wasps (currently 68400 records on the Barcode of Life Data Systems (BOLD) (Ratnasingham \& Hebert 2007)) and two major groups 1 of their hosts-Diptera and Lepidoptera (currently 87340 and 497200 BOLD records, respectively)—constitute a unique source of empirical data documenting primer amplification success. For this study, the reverse primer MLepR1 [initially named MH-MR1 (Hajibabaei et al. 2006a)] frequently used at the CCDB (used in 39156 PCR run at the CCDB by 5 September 2010) was thought to represent an ideal candidate because of its unique properties: (i) when used in conjunction with forward primer LepF1 (Hajibabaei et al. 2006a), it universally amplifies a 307-bp fragment of the barcode region in Diptera and Lepidoptera (Table 1); and (ii) by contrast, in Hymenoptera this primer was known to have very low affinity with the homologous binding site, and it has been systematically replaced by another oligomere in DNA barcoding studies (Smith et al. 2005, 2008). Matching the required properties_-short length, species-diagnostic amplicon, host universal and parasitoid exclusive-the pair LepF1/MLepR1 was selected to target host DNA in adult parasitoid wasps' guts.

\section{In silico comparison of primer fit}

For comparison of the fit between the primer MLepR1 and its binding site in parasitoid wasps and in their hosts, we assembled through BOLD three data sets based on publicly available sequences on GenBank for 
Table 1 Successful use of primer MLepR1 in Lepidoptera and Diptera*

\begin{tabular}{llll}
\hline Group & $\begin{array}{l}\text { Number of } \\
\text { families }\end{array}$ & $\begin{array}{l}\text { Number of } \\
\text { species }\end{array}$ & $\begin{array}{l}\text { Number of } \\
\text { samples }\end{array}$ \\
\hline $\begin{array}{l}\text { Lepidoptera } \\
\text { Diptera }\end{array}$ & 89 & 9262 & 26205 \\
\hline
\end{tabular}

*As reported in the Barcode of Life Data Systems (BOLD) from samples processed at the Canadian Centre for DNA Barcoding.

(i) six major families of parasitoid wasps (342 species in 186 genera, see Supporting Information Table S1); (ii) Lepidoptera (2711 species in 831 genera representing 42 families); and (iii) Diptera (1990 species in 417 genera representing 48 families). Sequences with ambiguous base calls in the binding region were excluded from the analysis. The nucleotide diversity for each locus of the binding site of MLepR1 was calculated using DNASP version 5.10.00 (Librado \& Rozas 2009). The comparison of primer fit and the measure of nucleotide diversity was carried out both for the full data set described earlier and for a subset of the GenBank sequences limited to one species per genus to exclude the possibility that densely sampled genera may overestimate the conservation of sites along the binding region of MLepR1.

\section{Test of MLepR1 amplification success in parasitoid wasps}

We used available DNA extracts from a selection of 297 parasitoid wasps (Table S3) collected as part of the PROBE campaign in Churchill (Manitoba, Canada) between 2006 and 2008. One half of these samples were part of a published study (Smith et al. 2009), and the other half resulted from the continued efforts to inventory the biota of this region. The DNA extraction protocol was identical for all samples (Smith et al. 2009). These wasps belong to eight subfamilies within two families, the Braconidae and Ichneumonidae (Table S3). Because of the strong taxonomic impediment affecting these insects, most species remain unidentified; though, morphological study and genetic divergences suggest that this data set encompasses more than 90 distinct species within more than 20 genera. The selected wasps have all been successfully sequenced for the barcode region of $\mathrm{COI}$ at the $\mathrm{CCDB}$ using the primer pairs LepF1/LepR1 targeting the full-length DNA barcode (658 bp), or alternatively LepF1/C_ANTMR1D, MLepF1/ LepR1 and RonMWaspDeg_t1/LepR1 targeting shorter sequences (see Smith et al. (2009) for detailed protocols). Sequences of all primers used are available at http:// 2 www.boldsystems.org/views/primerlist.php. The protocols used for these wasps are standard high-throughput protocols used routinely at the CCDB (available here: http:/ / www.dnabarcoding.ca/pa/ge/research/protocols). We carried out polymerase chain reactions (PCR) for these 297 samples with the primer pair LepF1/MLepR1 in $12.5 \mu \mathrm{L}$ reaction volumes containing $2.5 \mathrm{~mm}$ $\mathrm{MgCl} 2,1.25 \mathrm{pm}$ of each primer, $50 \mu \mathrm{M}$ dNTPs, $10 \mathrm{~mm}$ Tris- $\mathrm{HCl}(\mathrm{pH} 8.3), 50 \mathrm{~mm} \mathrm{KCl}, 10-20 \mathrm{ng}(1-2 \mu \mathrm{L})$ of genomic DNA and $0.3 \mathrm{U}$ of Taq DNA polymerase (Platinum Taq DNA polymerase; Invitrogen). The thermocycling profile consisted in one initial denaturation step of $1 \mathrm{~min}$ at $94{ }^{\circ} \mathrm{C}$, followed by five cycles of $40 \mathrm{~s}$ at $94{ }^{\circ} \mathrm{C}$, $40 \mathrm{~s}$ at $45^{\circ} \mathrm{C}$ and $1 \mathrm{~min}$ at $72{ }^{\circ} \mathrm{C}$, followed by 35 cycles of $40 \mathrm{~s}$ at $94{ }^{\circ} \mathrm{C}, 40 \mathrm{~s}$ at $51{ }^{\circ} \mathrm{C}$ and $1 \mathrm{~min}$ at $72{ }^{\circ} \mathrm{C}$, with a final extension step of $5 \mathrm{~min}$ at $72{ }^{\circ} \mathrm{C}$. Products were visualized on a $2 \%$ agarose E-Gel 96-well system (Invitrogen), and unpurified samples revealing faint to strong bands were cycle sequenced unidirectionally (with primer LepF1) in $10 \mu \mathrm{L}$ reaction volumes containing: $0.25 \mu \mathrm{L}$ of BigDye v3.1, $1.875 \mu \mathrm{L}$ of $5 \times$ ABI sequencing buffer, $5 \mu \mathrm{L}$ of $10 \%$ trehalose, $1 \mu \mathrm{L}$ of $10 \mu \mathrm{M}$ primer, $0.875 \mu \mathrm{L}$ of ultrapure water and $1 \mu \mathrm{L}$ of PCR product. The following thermocycling profile was used: initial denaturation at $96{ }^{\circ} \mathrm{C}$ for $2 \mathrm{~min}$, followed by 30 cycles of $96{ }^{\circ} \mathrm{C}$ for $30 \mathrm{~s}$, annealing at $55{ }^{\circ} \mathrm{C}$ for $15 \mathrm{~s}$ and extension at $60{ }^{\circ} \mathrm{C}$ for $4 \mathrm{~min}$. Sequence reads were generated on an ATBI 3730xl DNA Analyser (Applied Biosystems) after clean-up with Sephadex (Sigma-Aldrich). Sequences were trimmed and edited in Sequencher version 4.0.5 (Gene Codes) and subsequently identified by searching for best matches using the identification engine of BOLD (http:/ / www.barcodinglife.com/views/idrequest.php), querying for every COI barcode record in the database with a minimum length of $500 \mathrm{bp}$.

\section{Detection of host DNA from gut content analysis of reared parasitoid wasps}

To test for the detection of host DNA within the gut contents of parasitoid wasps, we gathered reared specimens of parasitoid wasps belonging to three species. Pediobius saulius, a European eulophid wasp, is a generalist parasitoid of leaf-mining insects, with more than 110 host species reported to date (Noyes 2002). Adult Pediobius wasps emerge directly from the pupa of the host, chewing their way out and possibly ingesting fresh host tissues when doing so. The 89 specimens we processed were reared from wild-collected overwintering pupae of microlepidoptera hosts. They emerged in individual tubes from field-collected leaf fragments containing the parasitized pupae and were killed immediately after emergence, precluding host feeding; specimens were further labelled and preserved dry in a tube. Overall, the specimens were collected between May 2002 and July 2007, with the majority of them 
being 6-14 months old at the time of DNA extraction. Hosts were identified based on food-plant usage and mine morphology: 78 individuals were derived from the pest species Cameraria ohridella and 11 from species of the genus Phyllonorycter; all host taxa belong to family Gracillariidae. Collection of the wasps Microplitis plutellae and Cotesia sp. were from the Canadian National Collection of Insects, Arachnids and Nematodes. These wasps were reared on the diamondback moth, Plutella xylostella, which is a pest for cultivated Brassicaceae. Specimens of both species (14 of M. plutellae and 17 of Cotesia sp.) were collected in rearing cages and killed in $95 \%$ ethanol in which they were preserved for about three weeks before being processed for DNA extraction. In contrast to the Pediobius wasps, the larvae of these two parasitoid species erupt from the host larva immediately after they complete their development and then spin a case outside the host and have no further contact with it or its remains. Moreover, the adult wasps of Cotesia and Microplitis do not feed on host haemolymph.

As host DNA is expected to be present in very small quantity within the gut of these very tiny wasps, special care was taken to reduce the risks of contamination in the laboratory. In addition to thorough cleaning of workspace and instruments, pre-PCR steps were carried out in an isolated room, excluding any contact with post-PCR products. Abdomens were removed from specimens under a stereomicroscope and placed in 96well plates. The forceps used were sterilized by flame between each individual wasp. DNA was extracted using the manual protocol developed for high-throughput production of DNA barcodes at the CCDB (Ivanova et al. 2006). Each sample first went through a 24-h incubation period at $56{ }^{\circ} \mathrm{C}$ in a $50 \mu \mathrm{L}$ solution of lysis buffer containing proteinase $\mathrm{K}(2 \mathrm{mg} / \mathrm{mL})$. DNA extraction was then performed using PALL2 $(3.0-\mu \mathrm{m})$ Glass Fiber plates (AcroPrep) with a final DNA elution step reduced to $30 \mu \mathrm{L}$ of sterile $\mathrm{ddH}_{2} \mathrm{O}$ (at $56{ }^{\circ} \mathrm{C}$ ) per sample. Two PCR were carried out for all samples, with primer pairs: (i) LepF1/LepR1, targeting wasp DNA; and (ii) LepF1/MLepR1 targeting the host DNA. Samples that failed with LepF1/LepR1 went through a second pass of PCR amplifications targeting shorter fragment of the wasp DNA barcode with primer pairs LepF1/C_ANTMR1D and MLepF1/LepR1. Sequencing was unidirectional (using either LepF1 or LepR1), except for the PCR products resulting from amplification with LepF1/LepR1. PCR and sequencing solutions and thermocycling profiles were identical to those described in the previous section. Sequence identification was performed using the BOLD identification engine. Match sequences for host species are publicly available in BOLD projects GRPUB, CAMER and ACRPL, and in GenBank with accession numbers EF380067 (Plutella xylostella), GQ144203 (Cameraria ohridella), GU146064 (Phyllonorycter platani) and GU146063 (Ph. esperella). All sequences generated for this publication or $\mathbf{3}$ used for analysis are publicly accessible in BOLD within projects HYGUT ('Host Identification from Parasitoid Gut-contents'), BACAS ('Barcode Accumulation Curves') and BACX ('Churchill Parasitoid BAC II'). They have also been deposited in GenBank. Accession numbers for the 297 wasps samples used to test for primer amplification success are given in Table S3; those for the reared parasitoid wasps are GU086892 to GU086908, GU087007 to GU087020, and GU07050 to GU087126; the host sequences are GU086874 to GU086890 and GU087134 to GU087145.

\section{Results}

The in silico analysis of primer fit confirmed the empirically reported properties of primer MLepR1. In parasitoid wasps, we observed consistent mismatches between the $3^{\prime}$ end of the MLepR1 sequence and the corresponding segment of the binding site (Fig. 1a; Tables S1 and S2), a condition explaining the poor binding success of the primer in these insects. A similar comparison in
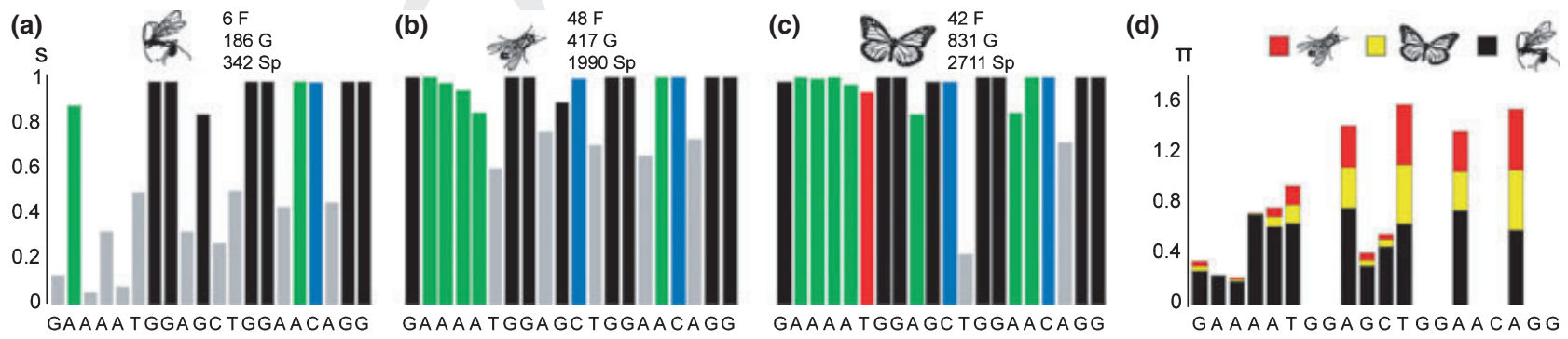

Fig. 1 In silico analysis of primer MLepR1 match in parasitoid wasps and their two main groups of hosts. a-c: Similarity (s) between primer MLepR1 (horizontal axis, reverse complement) and its binding site derived from GenBank sequences of COI in Hymenoptera (a), Diptera (b) and Lepidoptera (c) (number of families (F), genera (G) and species (Sp) are given above charts); the nucleotides are colour coded by base pair when similarity is higher than $80 \%$. d: Site variation $(\pi)$ along MLepR1 in analysed GenBank sequences for the three insect orders. 
Lepidoptera and Diptera shows a close match and high conservation of the binding site of MLepR1 in these groups (Fig. 1b-d; Table S2), supporting the near universality of this primer as reported empirically (Table 1).

We further established the poor binding affinities of MLepR1 in parasitoid wasps using it in conjunction with the universal forward primer LepF1 (Hajibabaei et al. 2006a) to amplify the first $307 \mathrm{bp}$ of the barcode fragment in a set of 297 samples of parasitoid wasps (Table S3). DNA of these wasp samples had been previously amplified successfully with the same forward primer, but with an alternate reverse primer. As predicted from the in silico approach, the amplification failed in all but nine samples (3\%; Fig. 2); in these samples, the primer pair LepF1/MLepR1 actually amplified unexpectedly a 733-bp fragment of COI, with MLepR1 binding to a nontarget region of the gene. These properties of MLepR1-i.e. universality in Lepidoptera and Diptera, and consistent failure in Hymenoptera-make it a perfect candidate to target host DNA within the guts of parasitoid wasps. In contrast to group-specific primers generally designed for DNA analysis of gut

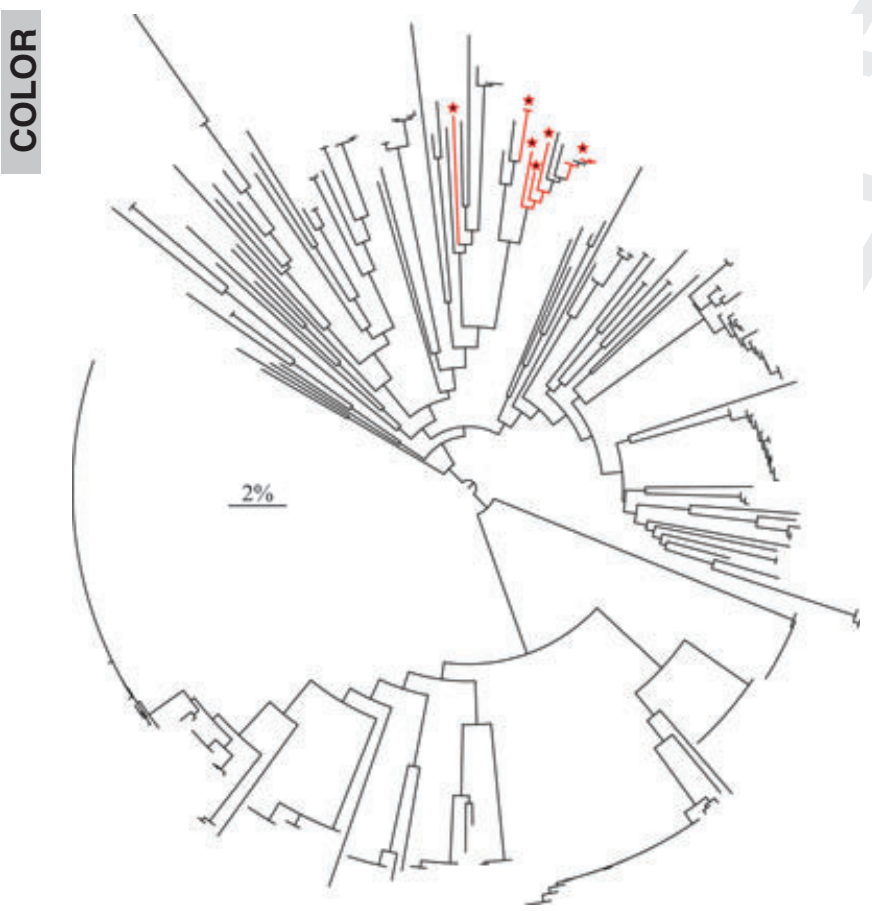

Fig. 2 Amplification success of primer MLepR1 in parasitoid wasps. Only 9 (highlighted terminals) of 297 samples of parasitoid wasps (Table S3) were successfully amplified and sequenced using primer MLepR1 associated with a universal forward primer. The neighbour-joining (NJ) tree was built with the 297 DNA barcodes generated from leg-derived DNA extracts amplified with universal insect primers (see text). contents (Chen et al. 2000; Sheppard et al. 2004; Harper et al. 2005; Admassu et al. 2006; King et al. 2008), MLepR1 has the unique property of being near-universal in the two main groups of hosts, thus permitting its use in spite of limited a priori knowledge about the identity of the target taxon-a scenario closely approximating the norm with parasitoid-host relationships.

Using the primer pair LepF1/MLepR1 to amplify host DNA from the 120 abdomen-derived DNA extracts of the three species of reared wasps, we obtained 36 amplifications. All these PCR products were processed through sequencing and 29 of the 120 samples (24\%) representing all three wasp species (Fig. 3) eventually produced sequences of length and quality suitable for reliable identification of the host. Only in one case did the host DNA sequence match a species different from the expected host (Fig. 3); in this case, the host appears to be an unidentified species of leaf miner in the genus Phyllonorycter $(98.2 \%$ match to P. abrasella). As the wasps were reared from field-collected leaf-mines, this probably reflects the overlooked use of the same host plant by two species of leaf miners. Host DNA was successfully detected both in wasps emerging from a case outside the host (Cotesia and Microplitis) and in wasps (Pediobius) chewing their way out of the microlepidoptera pupa when emerging. Thus, host tissue ingestion during emergence is not the sole source of the host DNA detected by our analyses. In the absence of host feeding in the three wasp species we used in our experiments, it is clear that successful amplification and sequencing of host DNA occurred in a number of individuals which had not ingested host DNA since their last larval meal. Finally, when using other primer pairs on the same DNA extracts, we obtained diagnostic DNA sequences for the wasp species in 108 of the 120 samples.

\section{Discussion}

By successfully identifying the host used by a parasitoid wasp through the molecular analysis of the gut contents of its adult, and by excluding other postmetamorphosis sources of host DNA (host feeding and tissue ingestion during emergence), our results provide the first evidence for the persistence of ingested DNA through metamorphosis in holometabolous insects. While our study provides a new example of how molecular methods can provide unsuspected opportunities in biology (Pond et al. 2009; Shokralla et al. 2010), it also illustrates how much remains to be learned about the physiology of insects. In spite of the rapid development of DNAbased analyses of gut contents (King et al. 2008), very little is known about how long ingested DNA remains detectable within the gut tracts of predatory insects 

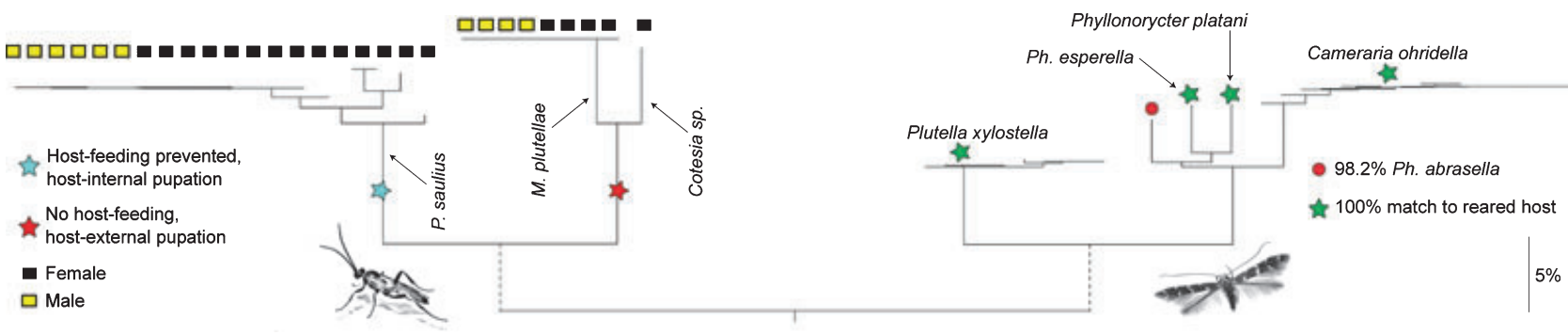

Fig. 3 Distance analysis (NJ) of COI sequences derived from parasitoid wasps' abdomens. This tree combines DNA sequences of parasitoid wasps and their microlepidoptera hosts as generated from PCR amplicons obtained from DNA extracted of the abdomens of 29 parasitoid wasps. The sequences for samples on the left-hand side of the tree were obtained with the primer pairs LepF1/LepR1, or LepF1/C_ANTMR1D and MLepF1/LepR1; they represent the wasp DNA. The sequences on the right-hand side of the tree were obtained from the same DNA extracts with the primer pair LepF1/MLepR1; they all match the known microlepidoptera host except in one case (red circle, see text).

(Greenstone et al. 2007). Experimental assessments of the half-lives of ingested DNA have only examined a few taxonomic groups, and they were shown to be very variable, ranging from few hours (Chen et al. 2000; McMillan et al. 2007) to several days (Sheppard et al. 2005; Greenstone et al. 2007), possibly because of variation in the metabolic rates of the predators. We note that in some parasitoids, metamorphosis can occur within a few days (Sequeira \& Mackauer 1992; Harvey \& Strand 2003), a time period compatible with the persistence of host DNA through incomplete digestion. Moreover, the half-life of DNA within the guts of the parasitoid larva and throughout its subsequent metamorphosis may be significantly extended because of the dramatic reorganization of the digestive tract (Hakim et al. 2010) and its reconfiguration for the use of a different food source (Jervis et al. 1993).

In practice, further studies are needed to assess the applicability of the approach in other groups of holometabolous insects with similar characteristics and to develop other group-specific protocols. Success will certainly be affected by the life history traits of target species. In particular, we anticipate that accounting for factors like pupation time, adult lifetime before capture and the possible occurrence of secondary predation (King et al. 2008) will be critical in designing studies based on our approach. Species with continuous generations in the tropics may produce uniform results throughout the year, whereas reduced efficacy might be expected for univoltine species in temperate regions. Here, the second (or later) generation of multivoltine species will probably yield better results. However, our success in detecting host usage by Pediobius saulius whose adults emerged after overwintering in the pupae of their host suggests that a long pupation period does not preclude host DNA detection. Furthermore, while our studies established that ingestion of host DNA after metamorphosis was not required for success, further experiments may reveal that success rates in the field are higher for females of species that feed on their hosts, or in those species that pupate inside the body of the host and ingest host tissues when emerging. Any negative effect on host DNA degradation of time following ingestion could be balanced by targeting a shorter DNA fragment through the use of an alternative forward primer closer to the MLepR1 binding site, thus increasing the recovery rate for host DNA while still permitting reliable host identification (Hajibabaei et al. 2006b; Meusnier et al. 2008).

In parasitoid wasps, the use of this approach-here named molecular analysis of parasitoid linkages (MAPL) - in parallel with the development of host and wasp DNA barcode libraries (Janzen et al. 2009; Hebert et al. 2010), has the potential to revolutionize our knowledge of host-parasitoid relationships, with large effects on our understanding of food webs and community ecology (Morris et al. 2004; Valentini et al. 2009) and of host-parasitoid co-evolution. Examining multiple individuals of a single wasp species will, for instance, provide information on host ranges and offer a novel means to test for the prevalence of specialist or generalist parasitoid species, which can now be determined simply through MAPL analysis of adult wasps. Because MAPL allows researchers to use the same DNA extracts to target both the parasitoid wasp's DNA barcode and the homologous sequence of its host, we recommend incorporating it in high-throughput DNA barcoding workflows. Here, the traditionally used tissue source (leg) would be replaced by analysis of the entire abdomen of the wasp, with an additional PCR (LepF1/MLepR1), followed by sequencing of all amplified products. Nondestructive protocols are already in place (Porco et al. 2009), permitting the recovery of tissue samples after DNA extraction if the abdomens are needed for morphological study. Gut content analyses, like forensics, are very sensitive to 
contamination issues, and protocols must be carried out with special precautions with respect to how specimens are collected, handled and processed. Collecting methods such as Malaise traps, commonly used to collect parasitoid wasps, are likely inappropriate because of the risk of ethanol-derived contaminations (King et al. 2008; Shokralla et al. 2010), so we recommend restricting analysis to specimens collected with sweep nets or with interception devices that do not include immersion in ethanol. If used systematically, MAPL has immediate applications in the agriculture sciences by facilitating and selecting biological control agents. Parasitoid wasps are the most commonly used organisms to control populations of pests and invasive species (Greathead 1986) and using MAPL to screen host-parasitoid associations of invasives in their area of origin, one could reliably identify the best control agents. Alternatively, developing a database documenting host-parasitoid relationships based on MAPL will create a very valuable resource for the future identification and selection of pest natural enemies. MAPL also offers a new way to monitor and possibly control the effects of introduced biological agents on indigenous organisms (Gariepy et al. 2008) by revealing the use of nontarget hosts by the parasitoid wasps. Our results open a new window into food web quantification. We predict that the integration of MAPL into DNA barcoding workflows will drastically accelerate the registration of host-parasitoid associations and that the development of similar approaches for other orders of insects with complete metamorphosis will be equally productive.

\section{Acknowledgements}

The authors thank A. M. Farmakis, M. Kenis, S. Augustin and R. Tomov for providing the reared wasps. J. Huber, J. Casas and D. H. Janzen kindly commented on an earlier version of the manuscript. This research was supported by grants from Genome Canada through the Ontario Genomics Institute, the Canada Foundation for Innovation, the Ontario Innovation Trust and NSERC to PDNH.

\section{References}

Admassu B, Juen A, Traugott M (2006) Earthworm primers for DNA-based gut content analysis and their cross-reactivity in a multi-species system. Soil Biology and Biochemistry, 38, 1308-1315

Chen Y, Giles KL, Payton ME, Greenstone MH (2000) Identifying key cereal aphid predators by molecular gut analysis. Molecular Ecology, 9, 1887-1898.

Dunshea G (2009) DNA-based diet analysis for any predator. PLOS ONE, 4, e5252.

Eveleigh ES, McCann KS, McCarthy PC et al. (2007) Fluctuations in density of an outbreak species drive diversity cascades in food webs. Proceedings of the National Academy of Sciences, 104, 16976-16981.

Gariepy TD, Kuhlmann U, Gillott C, Erlandson M (2007) Parasitoids, predators and PCR: the use of diagnostic molecular markers in biological control of Arthropods. Journal of Applied Entomology, 131, 225-240.

Gariepy TD, Kuhlmann U, Gillott C, Erlandson M (2008) A largescale comparison of conventional and molecular methods for the evaluation of host-parasitoid associations in non-target risk-assessment studies. Journal of Applied Ecology, 45, 708-715.

Godfray HCJ (1994) Parasitoids: Behavioral and Evolutionary Ecology. ???????, Princeton, USA.

Greathead DJ (1986) Parasitoids in classical biological control In:Insect Parasitoid (eds Waage J, Greathead DJ), pp. 289-318. Academic Press, London.

Greenstone $\mathrm{MH}$, Rowley DL, Weber DC, Payton ME, Hawthorne DJ (2007) Feeding mode and prey detectability half-lives in molecular gut-content analysis: an example with two predators of the Colorado potato beetle. Bulletin of Entomological Research, 97, 201-209.

Hajibabaei M, deWaard JR, Ivanova NV et al. (2005) Critical factors for assembling a high volume of DNA barcodes. Philosophical Transactions of the Royal Society of London, B, 360, 1959-1967.

Hajibabaei M, Janzen DH, Burns JM, Hallwachs W, Hebert PDN (2006a) DNA barcodes distinguish species of tropical Lepidoptera. Proceedings of the National Academy of Sciences, 103, 968-971.

Hajibabaei M, Smith MA, Janzen DH et al. (2006b) A minimalist barcode can identify a specimen whose DNA is degraded. Molecular Ecology Notes, 6, 959-964.

Hakim RS, Baldwin K, Smagghe G (2010) Regulation of midgut growth, development, and metamorphosis. Annual Review of Entomology, 55, 593-608.

Harper GL, King RA, Dodd CS et al. (2005) Rapid screening of invertebrate predators for multiple prey DNA targets. Molecular Ecology, 14, 819-827.

Harvey JA, Strand MR (2003) Sexual size and development time dimorphism in a parasitoid wasp: an exception to the rule? European Journal of Entomology, 100, 485-492.

Hebert PDN, Cywinska A, Ball SL, deWaard JR (2003a) Biological identifications through DNA barcodes. Proceedings of the Royal Society of London, B, 270, 313-321.

Hebert PDN, Ratnasingham S, DeWaard JR (2003b) Barcoding animal life: cytochrome $\mathrm{c}$ oxidase subunit 1 divergences among closely related species. Proceedings of the Royal Society of London, B, 270, S96-S99.

Hebert PDN, DeWaard JR, Landry JF (2010) DNA barcodes for 1/1000 of the animal kingdom. Biology Letters, 6, 359-362.

Ivanova NV, deWaard JR, Hebert PDN (2006) An inexpensive, automation-friendly protocol for recovering high-quality DNA. Molecular Ecology Notes, 6, 998-1002.

Janzen DH, Hallwachs W, Blandin P et al. (2009) Integration of DNA barcoding into an ongoing inventory of complex tropical biodiversity. Molecular Ecology Resources, 9, 1-26.

Jervis M, Kidd N, Walton M (1992) A review of methods for determining dietary range in adult parasitoids. BioControl, 37, 565-574.

Jervis MA, Kidd NAC, Fitton MG, Huddleston T, Dawah HA (1993) Flower-visiting by hymenopteran parasitoids. Journal of Natural History, 27, 67-105. 
King RA, Read DS, Traugott M, Symondson WOC (2008) Molecular analysis of predation: a review of best practice for DNA-based approaches. Molecular Ecology, 17, 947-963.

Librado P, Rozas J (2009) DnaSP v5: a software for comprehensive analysis of DNA polymorphism data. Bioinfomatics, 25, 1451-1452.

McMillan S, Kuusk A-K, Cassel-Lundhagen A, Ekbom B (2007) The influence of time and temperature on molecular gut content analysis: Adalia bipunctata fed with Rhopalosiphum padi. Insect Science, 14, 353-358.

Meusnier I, Singer G, Landry J-F et al. (2008) A universal DNA mini-barcode for biodiversity analysis. BMC Genomics, 9, 214.

Morris RJ, Lewis OT, Godfray HCJ (2004) Experimental evidence for apparent competition in a tropical forest food web. Nature, 428, 310-313.

Noyes JS (2002) Interactive Catalogue of World Chalcidoidea 2001

6 (CD-ROM), 2nd edn. Taxapad, Vancouver, Canada.

Pond SK, Wadhawan S, Chiaromonte F et al. (2009) Windshield splatter analysis with the Galaxy metagenomic pipeline.

7 Genome Research, doi: 10.1101/gr.094508.109.

Porco D, Rougerie R, Deharveng L, Hebert PDN (2009) Coupling non-destructive DNA extraction and voucher retrieval for small soft-bodied Arthropods in a highthroughput context: the example of Collembola. Molecular

8 Ecology Resources, doi: 10.1111/j.1755-0998.2010.2839.x.

Ratnasingham S, Hebert PDN (2007) BOLD: The Barcode of Life Data System (http://www.barcodinglife.org). Molecular Ecology Notes, 7, 355-364.

Sequeira R, Mackauer M (1992) Nutritional ecology of an insect host-parasitoid association: the pea aphid-Aphidius ervi system. Ecology, 73, 183-189.

Sheppard SK, Harwood JD (2005) Advances in molecular ecology: tracking trophic links through predator-prey foodwebs. Functional Ecology, 19, 751-762.

Sheppard SK, Henneman ML, Memmott J Symondson WOC (2004) Infiltration by alien predators into invertebrate food webs in Hawaii: a molecular approach. Molecular Ecology, 13, 2077-2088.

Sheppard SK, Bell J, Sunderland KD et al. (2005) Detection of secondary predation by PCR analyses of the gut contents of invertebrate generalist predators. Molecular Ecology, 14, 44614468.

Shokralla S, Singer GAC, Hajibabaei M (2010) Direct PCR amplification and sequencing of specimens' DNA from preservative ethanol. BioTechniques, 48, 232-234.

Smith MA, Fisher BL, Hebert PDN (2005) DNA barcoding for effective biodiversity assessment of a hyperdiverse arthropod group: the ants of Madagascar. Philosophical Transactions of the Royal Society of London, B, 360, 1825-1834.
Smith MA, Rodriguez JJ, Whitfield JB et al. (2008) Extreme diversity of tropical parasitoid wasps exposed by iterative integration of natural history, DNA barcoding, morphology, and collections. Proceedings of the National Academy of Sciences, 105, 12359-12364.

Smith MA, Fernandez-Triana J, Roughley R, Hebert PDN (2009) DNA barcode accumulation curves for understudied taxa and areas. Molecular Ecology Resources, 9, 208-216.

Traugott M, Symondson WOC (2008) Molecular analysis of predation on parasitized hosts. Bulletin of Entomological Research, 98, 223-231.

Valentini A, Pompanon F, Taberlet P (2009) DNA barcoding for ecologists. Trends in Ecology \& Evolution, 24, 110-117.

Weathersbee AA, Shufran KA, Panchal TD, Dang PM, Evans GA (2004) Detection and differentiation of parasitoids (Hymenoptera: Aphidiidae and Aphelinidae) of the brown citrus aphid (Homoptera: Aphididae): species-specific polymerase chain reaction amplification of $18 \mathrm{~S}$ rDNA. Annals of the Entomological Society of America, 97, 286-292.

$\operatorname{xxxxxx}$

\section{Supporting information}

Additional supporting information may be found in the online version of this article:

Table S1 GenBank records used for comparisons of MLepR1 primer match in Hymenoptera (ProcessID = record accession number in BOLD)

Table S2 Similarity (s) and nucleotide diversity ( $\mathrm{Pi}$ ) values for each of the 20 sites of the binding region of MLepR1 (upper row) in GenBank sequences of Hymenoptera, Diptera and Lepidoptera (results for the GenBank data set reduced to one species per genus in Diptera and Lepidoptera are given within square brackets)

Table S3 Details of the 297 records used for testing amplification of parasitoid wasps' DNA with the primer pair LepF1/ MLepR1

Please note: Wiley-Blackwell are not responsible for the content or functionality of any supporting information supplied by the authors. Any queries (other than missing material) should be directed to the corresponding author for the article. 


\section{Author Query Form}

Journal: $\quad$ MEC

Article: $\quad 4918$

Dear Author,

During the copy-editing of your paper, the following queries arose. Please respond to these by marking up your proofs with the necessary changes/additions. Please write your answers on the query sheet if there is insufficient space on the page proofs. Please write clearly and follow the conventions shown on the attached corrections sheet. If returning the proof by fax do not write too close to the paper's edge. Please remember that illegible mark-ups may delay publication.

Many thanks for your assistance.

\begin{tabular}{|c|c|c|}
\hline Query reference & Query & Remarks \\
\hline 1 & $\begin{array}{l}\text { AUTHOR: Ratnasingham et al. } 2007 \text { has been changed to Ratnasingham and } \\
\text { Hebert } 2007 \text { so that this citation matches the Reference List. Please confirm } \\
\text { that this is correct. }\end{array}$ & \\
\hline 2 & $\begin{array}{l}\text { AUTHOR: Please check this website address and confirm that it is correct. } \\
\text { (Please note that it is the responsibility of the author(s) to ensure that all } \\
\text { URLs given in this article are correct and useable.) }\end{array}$ & \\
\hline 3 & AUTHOR: Please provide genus name for Ph. esperella. & \\
\hline 4 & $\begin{array}{l}\text { AUTHOR: Please provide the name of the publisher for reference Godfray } \\
\text { (1994). }\end{array}$ & \\
\hline 5 & $\begin{array}{l}\text { AUTHOR: Hebert et al. (2003a) has not been cited in the text. Please indicate } \\
\text { where it should be cited; or delete from the Reference List. }\end{array}$ & \\
\hline 6 & $\begin{array}{l}\text { AUTHOR: Please check and confirm the publisher name is correct for refer- } \\
\text { ence Noyes (2002). }\end{array}$ & \\
\hline 7 & $\begin{array}{l}\text { AUTHOR: Please provide the volume number, page range for reference Pond } \\
\text { et al. (2009). }\end{array}$ & \\
\hline 8 & $\begin{array}{l}\text { AUTHOR: Please provide the volume number, page range for reference Porco } \\
\text { et al. (2009). }\end{array}$ & \\
\hline 9 & $\begin{array}{l}\text { AUTHOR: Please supply a short paragraph about the research interest of the } \\
\text { authors. }\end{array}$ & \\
\hline
\end{tabular}




\section{USING E-ANNOTATION TOOLS FOR ELECTRONIC PROOF CORRECTION}

\section{Required Software}

Adobe Acrobat Professional or Acrobat Reader (version 7.0 or above) is required to e-annotate PDFs. Acrobat 8 Reader is a free download: http://www.adobe.com/products/acrobat/readstep2.html

Once you have Acrobat Reader 8 on your PC and open the proof, you will see the Commenting Toolbar (if it does not appear automatically go to Tools>Commenting>Commenting Toolbar). The Commenting Toolbar looks like this:

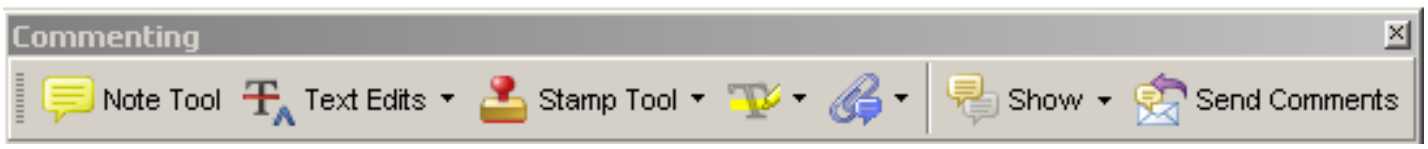

If you experience problems annotating files in Adobe Acrobat Reader 9 then you may need to change a preference setting in order to edit.

In the "Documents" category under "Edit - Preferences", please select the category 'Documents' and change the setting "PDF/A mode:" to "Never".



\section{Note Tool - For making notes at specific points in the text}

Marks a point on the paper where a note or question needs to be addressed.

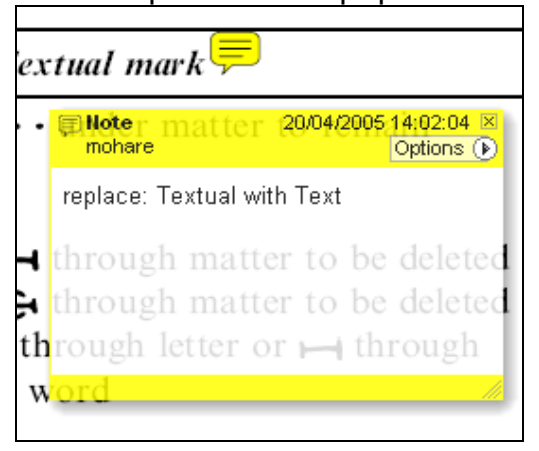

How to use it:

1. Right click into area of either inserted text or relevance to note

2. Select Add Note and a yellow speech bubble symbol and text box will appear

3. Type comment into the text box

4. Click the $X$ in the top right hand corner of the note box to close.

Replacement text tool - For deleting one word/section of text and replacing it

Strikes red line through text and opens up a replacement text box.

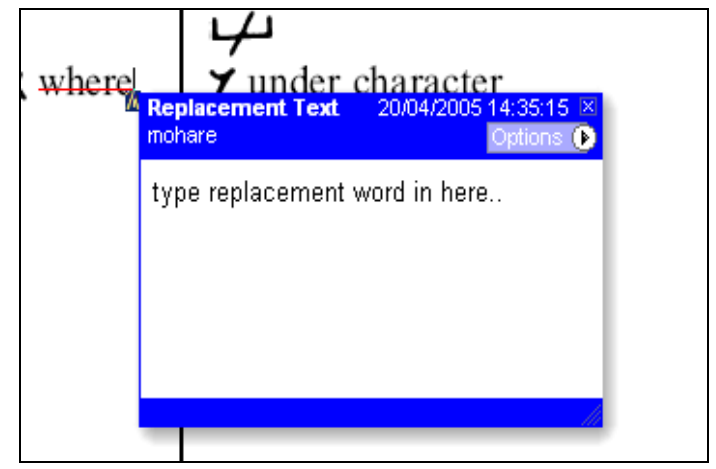

\section{How to use it:}

1. Select cursor from toolbar

2. Highlight word or sentence

3. Right click

4. Select Replace Text (Comment) option

5. Type replacement text in blue box

6. Click outside of the blue box to close

Cross out text tool - For deleting text when there is nothing to replace selection Strikes through text in a red line.

\begin{tabular}{|l|}
\hline substitute part of one or \\
more word(s) \\
Change to italies \\
Change to capitals \\
Change to small capitals \\
\hline
\end{tabular}
How to use it:
1. Select cursor from toolbar
2. Highlight word or sentence
3. Right click
4. Select Cross Out Text 


\section{(W)WILEY-BLACKWELL}

Approved tool - For approving a proof and that no corrections at all are required.

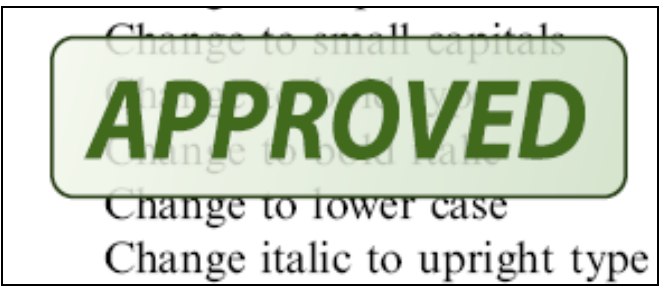

How to use it:

1. Click on the Stamp Tool in the toolbar

2. Select the Approved rubber stamp from the 'standard business' selection

3. Click on the text where you want to rubber stamp to appear (usually first page)

Highlight tool — For highlighting selection that should be changed to bold or italic. Highlights text in yellow and opens up a text box.

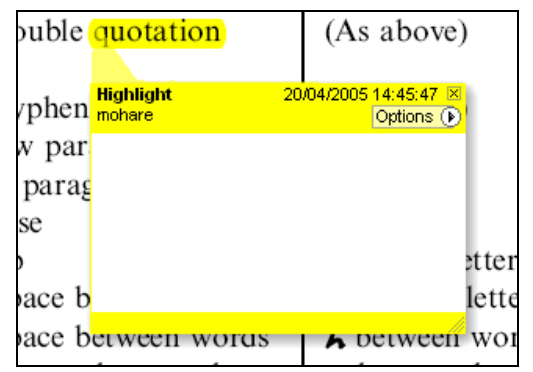

How to use it:

1. Select Highlighter Tool from the commenting toolbar

2. Highlight the desired text

3. Add a note detailing the required change

Attach File Tool - For inserting large amounts of text or replacement figures as a files. Inserts symbol and speech bubble where a file has been inserted.

\section{matter to be changed matter to matter to be changed matter to be changed} How to use it:

1. Click on paperclip icon in the commenting toolbar

2. Click where you want to insert the attachment

3. Select the saved file from your PC/network

4. Select appearance of icon (paperclip, graph, attachment or tag) and close

\section{Pencil tool - For circling parts of figures or making freeform marks}

Creates freeform shapes with a pencil tool. Particularly with graphics within the proof it may be useful to use the Drawing Markups toolbar. These tools allow you to draw circles, lines and comment on these marks.

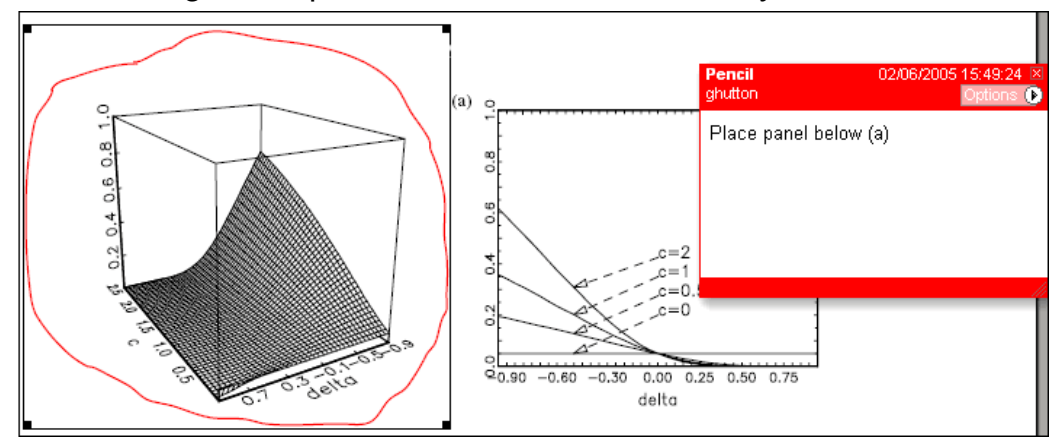

How to use it:

1. Select Tools $>$ Drawing Markups $>$ Pencil Tool

2. Draw with the cursor

3. Multiple pieces of pencil annotation can be grouped together

4. Once finished, move the cursor over the shape until an arrowhead appears and right click

5. Select Open Pop-Up Note and type in a details of required change

6. Click the $\mathrm{X}$ in the top right hand corner of the note box to close. 


\section{WILEY-BLACKWELL}

Help

For further information on how to annotate proofs click on the Help button to activate a list of instructions:

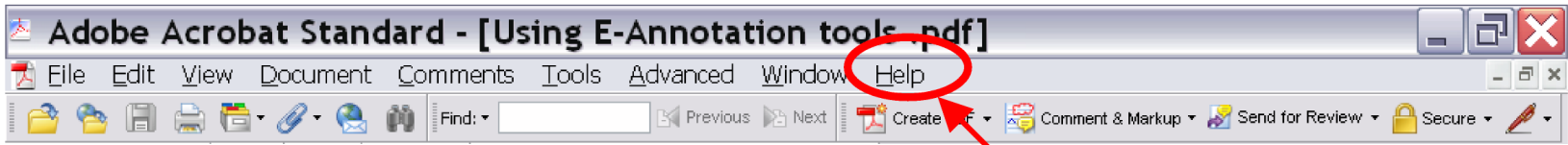

